\title{
SYNTHESIS, CHARACTERIZATION AND CRYSTAL STRUCTURES OF OXOVANADIUM(V) COMPLEXES DERIVED FROM SIMILAR AROYLHYDRAZONE LIGANDS
}

\author{
Xiu-Zhen Zhang ${ }^{1}$, Li-Xue Li ${ }^{2}$, Hai-Hua Li ${ }^{2}$, Zhonglu You ${ }^{2 *}$ and Hai-Liang Zhu ${ }^{1 *}$ \\ ${ }^{1}$ School of Life Sciences, Shandong University of Technology, ZiBo 255049, China \\ ${ }^{2}$ Department of Chemistry and Chemical Engineering, Liaoning Normal University, Dalian \\ 116029, China
}

(Received February 1, 2015; revised August 6, 2015)

\begin{abstract}
Reaction of $\left[\mathrm{VO}(\mathrm{acac})_{2}\right]$ (acac = acetylacetonate) with $N^{\prime}$-(5-chloro-2-hydroxybenzylidene)-3methoxybenzohydrazide $\left(\mathrm{H}_{2} \mathrm{~L}^{1}\right)$ and $N^{\prime}$-(2-hydroxy-4-methoxybenzylidene)-4-nitrobenzohydrazide $\left(\mathrm{H}_{2} \mathrm{~L}^{2}\right)$ in methanol affords methanol-coordinated mononuclear oxovanadium(V) complexes, [VOL $\left.{ }^{1}(\mathrm{OMe})(\mathrm{MeOH})\right](\mathbf{1})$ and $\left[\mathrm{VOL}^{2}(\mathrm{OMe})(\mathrm{MeOH})\right](2)$, respectively. The complexes were characterized by elemental analysis, FT-IR, ${ }^{1} \mathrm{H}$ NMR and ${ }^{13} \mathrm{C}$ NMR spectra. Crystal and molecular structures of the complexes were determined by single crystal $\mathrm{X}$-ray diffraction method. Single crystal X-ray structural studies indicate that the hydrazone ligands coordinate to the $\mathrm{VO}$ core through enolate oxygen, phenolate oxygen and azomethine nitrogen. The $\mathrm{V}$ atoms in the complexes are in octahedral coordination. Thermal stabilities of the complexes have also been studied.
\end{abstract}

KEY WORDS: Oxovanadium complex, Aroylhydrazone ligand, Crystal structure, X-ray diffraction, Thermal property

\section{INTRODUCTION}

Coordination chemistry of vanadium has attracted considerable attention in coordination and bioinorganic chemistry [1-5] as well as for the efficient catalytic properties in several organic synthesis procedures [6-9]. Schiff bases are a kind of interesting ligands in coordination chemistry [10-15]. In recent years, a number of vanadium complexes with Schiff bases derived from salicylaldehyde and primary amines have been reported [16-20]. Hydrazones, bearing $\mathrm{C}(\mathrm{O})-\mathrm{NH}-\mathrm{N}=\mathrm{CH}-$ groups, are a kind of special Schiff bases, which are of particular interest in coordination chemistry and biological applications. Vanadium complexes with hydrazone ligands have been reported to possess interesting biological activities [21] and catalytic properties [22]. However, oxovanadium(V) complexes derived from aroylhydrazone ligands have been much less studied when compared to other types of organic ligands. In the present work, we report the synthesis and structures of two new oxovanadium(V) complexes, $\left[\operatorname{VOL}{ }^{1}(\mathrm{OMe})(\mathrm{MeOH})\right](\mathbf{1})$ and $\left[\operatorname{VOL}^{2}(\mathrm{OMe})(\mathrm{MeOH})\right](2)$, where $\mathrm{L}^{1}$ and $\mathrm{L}^{2}$ are the dianionic forms of $N^{\prime}$-(5-chloro-2-hydroxybenzylidene)-3-methoxybenzohydrazide $\left(\mathrm{H}_{2} \mathrm{~L}^{1}\right)$ and $N^{\prime}-(2-$ hydroxy-4-methoxybenzylidene)-4-nitrobenzohydrazide $\left(\mathrm{H}_{2} \mathrm{~L}^{2}\right)$, respectively.<smiles>COc1cccc(C(=O)N/N=C/c2cc(Cl)ccc2O)c1</smiles>

*Corresponding author. E-mail: youzhonglu@126.com, hailiang_zhu@163.com 
Materials and measurements

\section{EXPERIMENTAL}

Commercially available 5-chlorosalicylaldehyde, 4-methoxysalicylaldehyde, 3-methoxybenzohydrazide and 4-nitrobenzohydrazide were purchased from Aldrich and used without further purification. $\left[\mathrm{VO}(\mathrm{acac})_{2}\right]$ was purchased from Shenyang Haizhongtian Chemical Company (China). Other solvents and reagents were made in China and used as obtained. $\mathrm{C}, \mathrm{H}$ and $\mathrm{N}$ elemental analyses were performed with a Perkin-Elmer elemental analyser. Infrared spectra were recorded on a Nicolet AVATAR 360 spectrometer as KBr pellets in the $4000-400 \mathrm{~cm}^{-1}$ region. Thermal stability analysis was performed on a Perkin-Elmer Pyris Diamond TG-DTA thermal analyses system. ${ }^{1} \mathrm{H}$ NMR and ${ }^{13} \mathrm{C}$ NMR spectra were recorded on a Bruker DPX 300 model spectrometer at $25{ }^{\circ} \mathrm{C}$ with TMS and solvent signals allotted as internal standards. Chemical shifts were reported in $\mathrm{ppm}(\delta)$.

Synthesis of $\mathrm{H}_{2} \mathrm{~L}^{1}$

5-Chlorosalicylaldehyde (1.0 mmol, $0.16 \mathrm{~g})$ and 3-methoxybenzohydrazide (1.0 mmol, $0.17 \mathrm{~g}$ ) were dissolved in methanol $(30 \mathrm{~mL})$ with stirring. The mixture was stirred for about $30 \mathrm{~min}$ at room temperature to give colorless solution. The solution was left still in air to slow evaporate of most of the solvent, to give crystalline product of $\mathrm{H}_{2} \mathrm{~L}^{2}$. The product was isolated by filtration and washed with cold methanol. Yield, $83 \%$; m.p. $181.0-182.5^{\circ} \mathrm{C}$. Analysis: found: $\mathrm{C} 59.23 \%$, $\mathrm{H} 4.26 \%$, N 9.07\%; calculated for $\mathrm{C}_{15} \mathrm{H}_{13} \mathrm{ClN}_{2} \mathrm{O}_{3}$ : C 59.12\%, $\mathrm{H} 4.30 \%$, N 9.19\%. IR data $\left(\mathrm{cm}^{-1}\right.$, $\mathrm{KBr}): 3447$ (w), 3195 (w), 1653 (s), 1611 (m), 1589 (m), 1561 (m), 1494 (s), 1435 (s), 1357 (w), $1332(\mathrm{w}), 1301(\mathrm{w}), 1267(\mathrm{~m}), 1153(\mathrm{~s}), 1114(\mathrm{~m}), 1080(\mathrm{~s}), 1035(\mathrm{~m}), 996(\mathrm{~m}), 853(\mathrm{~s})$, $781(\mathrm{w}), 745(\mathrm{w}), 727(\mathrm{w}), 546(\mathrm{w}), 470(\mathrm{w}) .{ }^{1} \mathrm{H}$ NMR (300 MHz, $d_{6}$-DMSO): $\delta 12.41(\mathrm{~s}, 1 \mathrm{H})$, $11.72(\mathrm{~s}, 1 \mathrm{H}), 8.61(\mathrm{~s}, 1 \mathrm{H}), 7.85(\mathrm{t}, 1 \mathrm{H}), 7.60(\mathrm{~m}, 2 \mathrm{H}), 7.38(\mathrm{~d}, 1 \mathrm{H}), 7.19(\mathrm{~d}, 1 \mathrm{H}), 6.91(\mathrm{~d}, 1 \mathrm{H})$, $6.85(\mathrm{~s}, 1 \mathrm{H}), 3.79(\mathrm{~s}, 3 \mathrm{H}) .{ }^{13} \mathrm{C}$ NMR $\left(75 \mathrm{MHz}, d_{6}\right.$-DMSO): $\delta 164.03,161.54,158.37,145.71$, $134.10,132.82,129.88,128.75,121.63,120.70,119.53,117.37,116.86,112.45,55.71$.

Synthesis of $\mathrm{H}_{2} \mathrm{~L}^{2}$

4-Methoxysalicylaldehyde (1.0 mmol, $0.15 \mathrm{~g})$ and 4-nitrobenzohydrazide (1.0 mmol, $0.18 \mathrm{~g})$ were dissolved in methanol $(30 \mathrm{~mL})$ with stirring. The mixture was stirred for about $30 \mathrm{~min}$ at room temperature to give yellow solution. The solution was left still in air to slow evaporate of most of the solvent, to give crystalline product of $\mathrm{H}_{2} \mathrm{~L}^{1}$. The product was isolated by filtration and washed with cold methanol. Yield, 87\%; m.p. 201.5-202.0 ${ }^{\circ} \mathrm{C}$. Analysis: found: C $56.92 \%$, $\mathrm{H} 4.08 \%$, N 13.47\%; calculated for $\mathrm{C}_{15} \mathrm{H}_{13} \mathrm{~N}_{3} \mathrm{O}_{5}$ : C 57.14\%, H 4.16\%, N 13.33\%. IR data $\left(\mathrm{cm}^{-1}\right.$, $\mathrm{KBr}): 3440$ (w), 3227 (w), 1642 (s), 1606 (s), 1516 (s), 1455 (w), 1348 (s), 1281 (s), 1228 (m), $1164(\mathrm{w}), 1122(\mathrm{w}), 1024(\mathrm{~m}), 963(\mathrm{w}), 909(\mathrm{w}), 853(\mathrm{~m}), 803(\mathrm{w}), 711(\mathrm{~m}), 636(\mathrm{w}), 607(\mathrm{w})$, $518(\mathrm{w}), 470(\mathrm{w}) .{ }^{1} \mathrm{H}$ NMR (300 MHz, $d_{6}$-DMSO): $\delta 12.25(\mathrm{~s}, 1 \mathrm{H}), 11.43(\mathrm{~s}, 1 \mathrm{H}), 8.57(\mathrm{~s}, 1 \mathrm{H})$, $8.38(\mathrm{~d}, 2 \mathrm{H}), 8.16(\mathrm{~d}, 2 \mathrm{H}), 7.48(\mathrm{~d}, 1 \mathrm{H}), 6.52(\mathrm{~d}, 2 \mathrm{H}), 3.77(\mathrm{~s}, 3 \mathrm{H}) .{ }^{13} \mathrm{C}$ NMR $\left(75 \mathrm{MHz}, d_{6^{-}}\right.$ DMSO): $\delta 164.15,162.37,161.96,152.13,145.22,139.10,133.37,129.75,123.16,112.11$, $105.78,102.19,55.67$.

\section{Synthesis of $\left[\mathrm{VOL}^{1}(\mathrm{OMe})(\mathrm{MeOH})\right](\mathbf{1})$}

A methanolic solution $(10 \mathrm{~mL})$ of $\left[\mathrm{VO}(\mathrm{acac})_{2}\right](0.1 \mathrm{mmol}, 27.0 \mathrm{mg})$ was added to a methanolic solution $(10 \mathrm{~mL})$ of $\mathrm{H}_{2} \mathrm{~L}^{1}(0.1 \mathrm{mmol}, 30.5 \mathrm{mg})$ with stirring. The mixture was stirred for $30 \mathrm{~min}$ to give a deep brown solution. The resulting solution was allowed to stand in air for a few days. Brown block-shaped crystals suitable for X-ray single crystal analysis were formed at the bottom of the vessel. The isolated product was washed three times with cold methanol, and dried in a vacuum over anhydrous $\mathrm{CaCl}_{2}$. Yield, 53\%. Analysis: found: $\mathrm{C} 47.0 \%, \mathrm{H} \mathrm{4.3 \% , \textrm {N }}$ 
6.4\%; calculated for $\mathrm{C}_{17} \mathrm{H}_{18} \mathrm{ClN}_{2} \mathrm{O}_{6} \mathrm{~V}$ : C 47.2\%, H 4.2\%, N 6.5\%. IR data ( $\left.\mathrm{cm}^{-1}, \mathrm{KBr}\right): 3445$ (w), 1603 (s), 1541 (m), 1450 (m), 1393 (s), 1287 (w), 1243 (w), 1186 (w), 1100 (m), 1047 (w), 998 (w), $960(\mathrm{~m}), 877(\mathrm{~s}), 823(\mathrm{w}), 781(\mathrm{w}), 723(\mathrm{~m}), 670(\mathrm{w}), 616(\mathrm{w}), 558(\mathrm{w})$.

\section{Synthesis of $\left[\mathrm{VOL}^{2}(\mathrm{OMe})(\mathrm{MeOH})\right](2)$}

Complex (2) was prepared by the same method as described for complex (1), with $\mathrm{H}_{2} \mathrm{~L}^{1}$

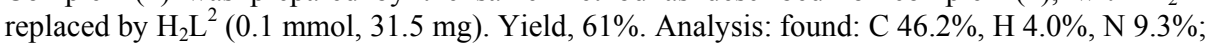
calculated for $\mathrm{C}_{17} \mathrm{H}_{18} \mathrm{~N}_{3} \mathrm{O}_{8} \mathrm{~V}$ : C 46.1\%, H 4.1\%, N 9.5\%. IR data $\left(\mathrm{cm}^{-1}, \mathrm{KBr}\right): 3445$ (w), 1600 (s), $1520(\mathrm{~m}), 1414$ (w), 1340 (s), 1245 (w), 1228 (m), 1132 (w), 1036 (w), 999 (m), 961 (m), $850(\mathrm{w}), 797(\mathrm{w}), 755(\mathrm{w}), 708(\mathrm{w}), 643(\mathrm{w}), 590(\mathrm{w}), 468(\mathrm{w})$.

Table 1. Crystallographic and experimental data for the complexes.

\begin{tabular}{|c|c|c|}
\hline & (1) & (2) \\
\hline Formula & $\mathrm{C}_{17} \mathrm{H}_{18} \mathrm{ClN}_{2} \mathrm{O}_{6} \mathrm{~V}$ & $\mathrm{C}_{17} \mathrm{H}_{18} \mathrm{~N}_{3} \mathrm{O}_{8} \mathrm{~V}$ \\
\hline FW & 432.7 & 443.3 \\
\hline Crystal shape/color & Black/brown & Black/brown \\
\hline Crystal size/ $\mathrm{mm}$ & $0.23 \times 0.20 \times 0.20$ & $0.17 \times 0.13 \times 0.12$ \\
\hline Crystal system & Triclinic & Monoclinic \\
\hline Space group & $P-1$ & $P 2_{1} / c$ \\
\hline$a / \AA$ & $7.346(2)$ & $21.672(1)$ \\
\hline$b / \AA$ & $11.841(3)$ & $8.5636(6)$ \\
\hline$c / \AA$ & $11.879(3)$ & $11.0682(7)$ \\
\hline$\alpha^{\infty}$ & $75.949(2)$ & 90 \\
\hline$\beta /^{\circ}$ & $72.381(2)$ & $103.329(2)$ \\
\hline$\gamma^{/ \rho}$ & $73.188(2)$ & 90 \\
\hline$V / \AA^{3}$ & $929.0(4)$ & $1998.9(2)$ \\
\hline$Z$ & 2 & 4 \\
\hline$T / \mathrm{K}$ & $298(2)$ & $298(2)$ \\
\hline$\mu / \mathrm{mm}^{-1}(\mathrm{Mo}-\mathrm{K} \alpha)$ & 0.715 & 0.545 \\
\hline$D_{c} / \mathrm{g} \mathrm{cm}^{-3}$ & 1.547 & 1.473 \\
\hline Reflections/parameters & $3404 / 250$ & $3701 / 268$ \\
\hline Independent reflections & 2652 & 3257 \\
\hline Restraints & 1 & 1 \\
\hline Index ranges $/ h, k, l$ & $-8,8 ;-14,14 ;-14,14$ & $-26,26 ;-10,10-1213$ \\
\hline$F(000)$ & 444 & 912 \\
\hline $\mathrm{T}_{\min }$ & 0.8529 & 0.9130 \\
\hline $\mathrm{T}_{\max }$ & 0.8703 & 0.9374 \\
\hline Goodness of fit on $F^{2}$ & 1.162 & 1.061 \\
\hline$R_{1}, w R_{2}[I \geq 2 \sigma(I)]^{\mathrm{a}}$ & $0.0733,0.1932$ & $0.0351,0.0954$ \\
\hline$R_{1}, w R_{2}$ (all data $)^{\mathrm{a}}$ & $0.0923,0.2013$ & $0.0409,0.1009$ \\
\hline Largest diff. peak and hole/e $\AA^{-3}$ & $0.646,-0.406$ & $0.360,-0.296$ \\
\hline
\end{tabular}

${ }^{\mathrm{a}} \mathrm{R}_{1}=\sum|| F_{\mathrm{o}}|-| F_{\mathrm{c}}|| \sum\left|F_{\mathrm{o}}\right|, w \mathrm{R}_{2}=\left[\sum w\left(F_{\mathrm{o}}^{2}-F_{\mathrm{c}}^{2}\right)^{2} / \sum w\left(F_{\mathrm{o}}^{2}\right)^{2}\right]^{1 / 2}$

\section{$X$-Ray diffraction}

Diffraction intensities for the complexes were collected at 298(2) K using a Bruker D8 Venture Photon diffractometer with MoK $\alpha$ radiation $(\lambda=0.71073 \AA)$. The collected data were reduced using SAINT [23], and multi-scan absorption corrections were performed using SADABS [24]. Structures of the complexes were solved by direct method and refined against $F^{2}$ by full-matrix least-squares methods using SHELXTL [25]. All the non-hydrogen atoms were refined anisotropically. The methanol $\mathrm{H}$ atoms in both complexes were located from difference Fourier 
maps and refined isotropically, with $\mathrm{O}-\mathrm{H}$ distance restrained to $0.85(1) \AA$. The remaining $\mathrm{H}$ atoms were placed in idealized positions and constrained to ride on their parent atoms. The crystallographic data for the complexes are summarized in Table 1. Selected bond lengths and angles are given in Table 2 .

Table 2. Selected bond lengths $(\AA)$ and angles $\left(^{\circ}\right)$ for the complexes.

\begin{tabular}{|c|c|c|c|c|c|c|c|}
\hline \multicolumn{4}{|c|}{ (1) } & \multicolumn{4}{|c|}{ (2) } \\
\hline $\mathrm{V} 1-\mathrm{O} 1$ & $1.857(4)$ & $\mathrm{V} 1-\mathrm{O} 2$ & $1.954(4)$ & V1-O1 & $1.8531(13)$ & $\mathrm{V} 1-\mathrm{O} 2$ & $1.9498(13)$ \\
\hline $\mathrm{V} 1-\mathrm{O} 4$ & $2.375(4)$ & $\mathrm{V} 1-\mathrm{O} 5$ & $1.759(4)$ & V1-O6 & $1.5763(16)$ & V1-O7 & $2.3421(14)$ \\
\hline $\mathrm{V} 1-\mathrm{O} 6$ & $1.567(5)$ & V1-N1 & $2.118(5)$ & V1-O8 & $1.7736(13)$ & V1-N1 & $2.1156(15)$ \\
\hline O6-V1-O5 & 103.2(2) & O6-V1-O1 & $99.5(2)$ & O6-V1-O8 & $102.86(8)$ & O6-V1-O1 & $101.37(8)$ \\
\hline O5-V1-O1 & $101.14(19)$ & O6-V1-O2 & $98.3(2)$ & O8-V1-O1 & $101.30(6)$ & O6-V1-O2 & $99.28(7)$ \\
\hline $\mathrm{O} 5-\mathrm{V} 1-\mathrm{O} 2$ & $94.70(19)$ & $\mathrm{O} 1-\mathrm{V} 1-\mathrm{O} 2$ & $152.71(18)$ & $\mathrm{O} 8-\mathrm{V} 1-\mathrm{O} 2$ & $93.51(6)$ & O1-V1-O2 & $151.11(6)$ \\
\hline O6-V1-N1 & $95.8(2)$ & O5-V1-N1 & $159.2(2)$ & O6-V1-N1 & $95.28(7)$ & O8-V1-N1 & $159.69(6)$ \\
\hline O1-V1-N1 & $83.84(18)$ & $\mathrm{O} 2-\mathrm{V} 1-\mathrm{N} 1$ & $73.93(17)$ & O1-V1-N1 & $83.74(6)$ & O2-V1-N1 & $74.41(5)$ \\
\hline O6-V1-O4 & $173.9(2)$ & O5-V1-O4 & $82.25(18)$ & O6-V1-O7 & $175.71(7)$ & O8-V1-O7 & $80.83(6)$ \\
\hline O1-V1-O4 & 82.01(18) & O2-V1-O4 & $78.26(16)$ & O1-V1-O7 & $79.87(6)$ & O2-V1-O7 & $78.18(5)$ \\
\hline N1-V1-O4 & $78.48(16)$ & & & N1-V1-O7 & $80.73(6)$ & & \\
\hline
\end{tabular}

General

\section{RESULTS AND DISCUSSION}

Replacement of two acetylacetonate ligands in $\left[\mathrm{VO}(\mathrm{acac})_{2}\right]$ by aroylhydrazone, methanol and methanolate ligands resulted in the mononuclear oxovanadium(V) complexes. The dinegative ligands are coordinated to the VO cores via the phenolate-oxygen, imino-nitrogen and enolateoxygen. The complexes are soluble in methanol, ethanol and acetonitrile. Molar conductance of the complexes at concentration of $10^{-4} \mathrm{M}$ is about $30 \Omega^{-1} \mathrm{~cm}^{2} \mathrm{~mol}^{-1}$, indicating they are nonelectrolyte [26].

IR spectra

The aroylhydrazone ligands showed stretching bands attributed to $\mathrm{C}=\mathrm{O}, \mathrm{C}=\mathrm{N}, \mathrm{C}-\mathrm{OH}$ and $\mathrm{NH}$ at about $1650,1605,1160$ and 1230 , and $3220 \mathrm{~cm}^{-1}$, respectively. The complexes exhibit two bands at about $960 \mathrm{~cm}^{-1}$, assigned to stretching vibrations of the $\mathrm{V}=\mathrm{O}$ groups [27]. The bands due to $v_{\mathrm{C}=\mathrm{O}}$ are absent in the complexes, but new $\mathrm{C}-\mathrm{O}$ stretch appeared at about $1245 \mathrm{~cm}^{-1}$. This suggests occurrence of keto-imine tautomerization of the aroylhydrazone ligands during complexation. The $v_{\mathrm{C}=\mathrm{N}}$ absorption observed at $1605 \mathrm{~cm}^{-1}$ in the free aroylhydrazone ligands shifted to $1600 \mathrm{~cm}^{-1}$ upon coordination to the $\mathrm{V}$ atoms [28].

\section{Thermal property}

Differential thermal (DT) and thermal gravimetric analyses (TGA) were conducted to examine the stability of the complexes (Figures 1 and 2). For the decomposition of complex (1), the first step started from $90{ }^{\circ} \mathrm{C}$ and ended at $110{ }^{\circ} \mathrm{C}$, corresponding to the loss of the ligand $\left(\mathrm{CH}_{3} \mathrm{OH}\right)$. The observed weight loss of $7.2 \%$ is close to the calculated value of $7.4 \%$. The second step, from $150{ }^{\circ} \mathrm{C}$ to $210{ }^{\circ} \mathrm{C}$, corresponds to the loss of the methanolate ligand $\left(\mathrm{CH}_{3} \mathrm{O}^{-}\right)$. The observed weight loss of $7.1 \%$ is close to the calculated value of $7.2 \%$. The last step, from $250{ }^{\circ} \mathrm{C}$ to 510 ${ }^{\circ} \mathrm{C}$, corresponds to the loss of the aroylhydrazone ligand $\left(\mathrm{C}_{15} \mathrm{H}_{11} \mathrm{ClN}_{2} \mathrm{O}_{3}{ }^{2-}\right)$, and the formation of the final product $\left(\mathrm{V}_{2} \mathrm{O}_{5}\right)$. The total weight loss of $79.3 \%$ is close to the calculated value of $79.0 \%$. For the decomposition of complex (2), there are several stages of decomposition, and it is very difficult to ascribe them. The complex decomposed from $100{ }^{\circ} \mathrm{C}$ and completed at 500 ${ }^{\circ} \mathrm{C}$. The total weight loss of $79.5 \%$ is the same as the calculated value of $79.5 \%$. 


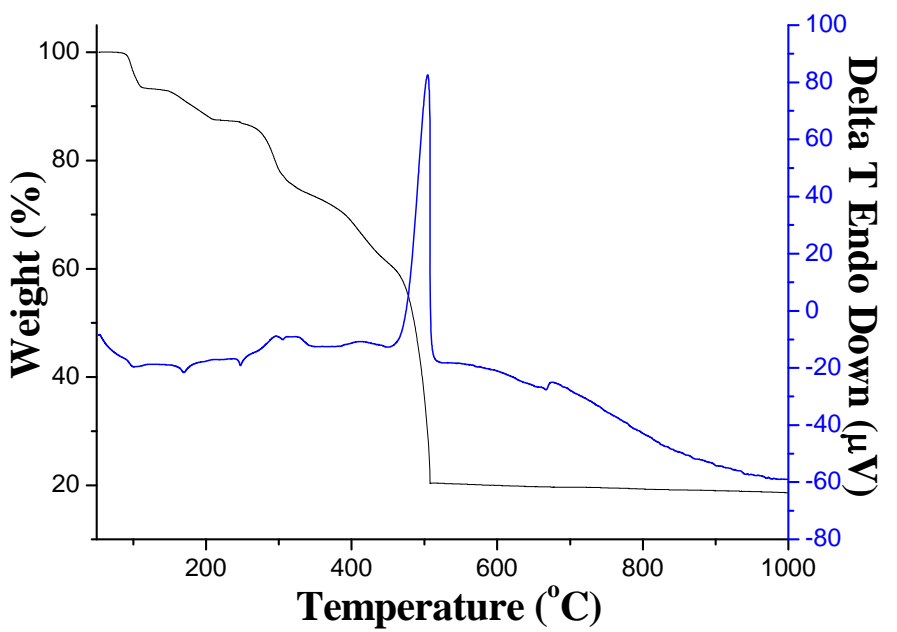

Figure 1. DT-TGA curves of complex (1).

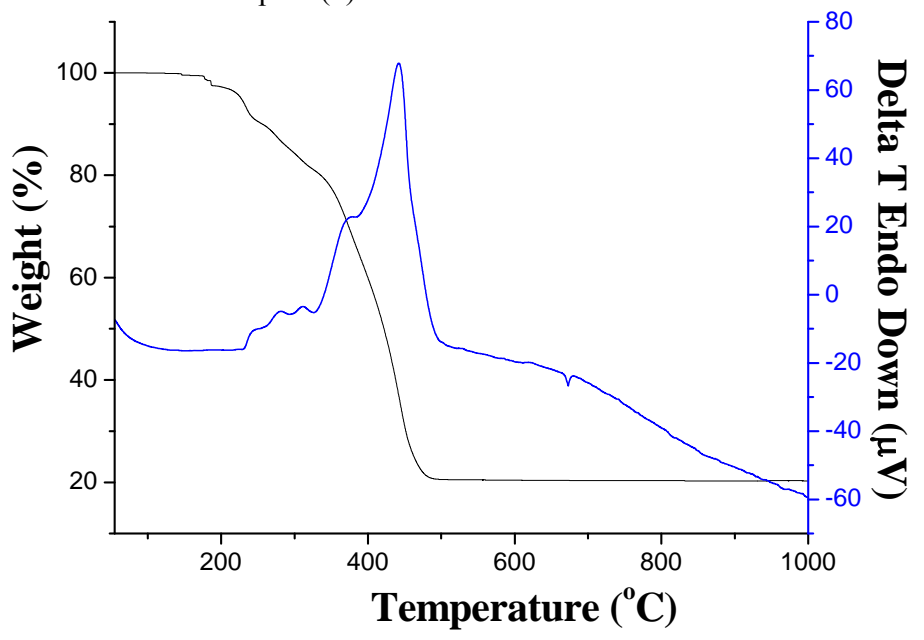

Figure 2. DT-TGA curves of complex (2).

\section{Structure description of the complexes}

Molecular structures and atom numbering schemes of the complexes are shown in Figures 3-6. Both structures are very similar except for the aroylhydrazone ligands. The $\mathrm{V}$ atoms in the complexes are in octahedral coordination, with the phenolate $\mathrm{O}$, azomethine $\mathrm{N}$ and enolate $\mathrm{O}$ atoms of the aroylhydrazone ligands as well as the methanolate $\mathrm{O}$ atom defining the equatorial plane, and with the methanol $\mathrm{O}$ atom and an oxo $\mathrm{O}$ atom locating at the axial positions. The $\mathrm{V}$ atoms deviate from the least-squares planes defined by the equatorial atoms by $0.314(1) \AA$ for (1) and 0.332(1) $\AA$ for (2). The coordinate bond lengths in both complexes are similar to each other, and also comparable to those observed in vanadium complexes with hydrazone ligands $[29,30]$. The distortion of the octahedral coordination can be observed from the coordinate bond angles, ranging from $73.93(17)$ to $103.2(2)^{\circ}$ for $(\mathbf{1})$, and from $74.41(5)$ to $102.86(8)^{\circ}$ for (2), for the perpendicular angles, and from $152.71(18)$ to $173.9(2)^{\circ}$ for (1), and from 151.11(6) to 
$175.71(7)^{\circ}$ for (2), for the diagonal angles. The dihedral angles between the benzene rings of the aroylhydrazone ligands are $9.7(3)^{\circ}$ for $(\mathbf{1})$ and $6.1(3)^{\circ}$ for $(\mathbf{2})$. In the crystal structure of complex (1), adjacent two molecules are linked through intermolecular $\mathrm{O}-\mathrm{H} \cdots \mathrm{N}$ hydrogen bonds [O4$\mathrm{H} 4=0.85(1) \AA, \mathrm{H} 4 \cdots \mathrm{N} 2^{\mathrm{i}}=2.13(5) \AA, \mathrm{O} 4 \cdots \mathrm{N} 2^{\mathrm{i}}=2.853(6) \AA, \mathrm{O} 4-\mathrm{H} 4 \cdots \mathrm{N} 2^{\mathrm{i}}=142(7)^{\circ}$; symmetry code for $\mathrm{i}: 1-x,-y, 2-z]$, to form a dimer (Figure 5). In the crystal structure of complex (2), molecules are linked through intermolecular $\mathrm{O}-\mathrm{H} \cdots \mathrm{N}$ hydrogen bonds $[\mathrm{O} 7-\mathrm{H} 7=$ $0.84(1) \AA, \mathrm{H} 7 \cdots \mathrm{N} 22^{\mathrm{ii}}=1.98(1) \AA, \mathrm{O} 7 \cdots \mathrm{N} 2^{\mathrm{ii}}=2.817(2) \AA, \mathrm{O} 7-\mathrm{H} 7 \cdots \mathrm{N} 2^{\mathrm{ii}}=173(3)^{\circ}$; symmetry code for ii: $x, 1 / 2-y, 1 / 2+z]$, to form 1D chains along the $c$ axis (Figure 6).

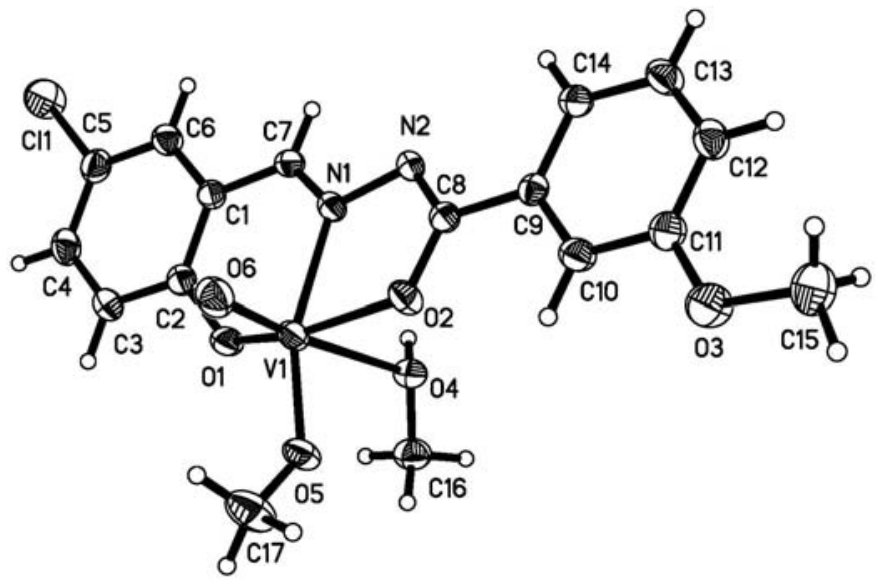

Figure 3. Molecular structure of complex (1) at 30\% probability displacement.

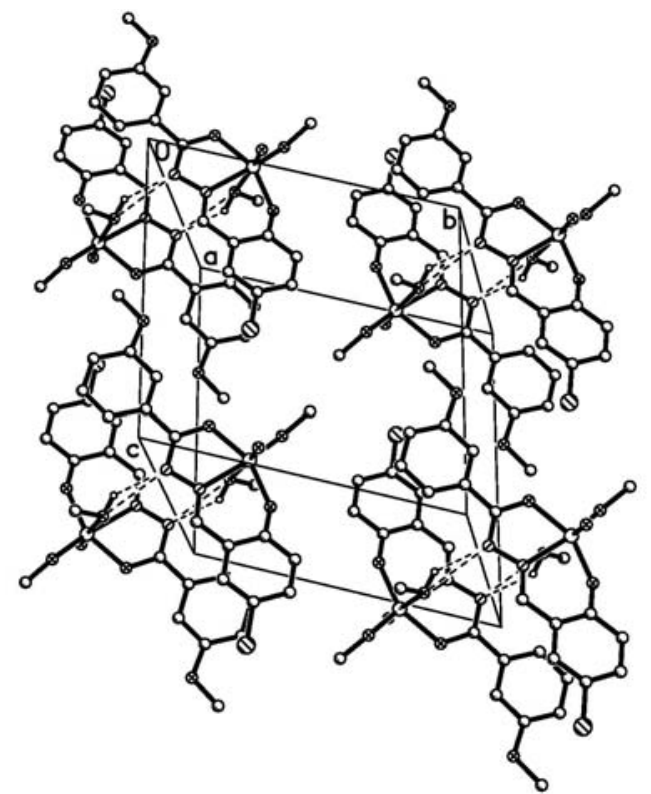

Figure 4. Molecular packing of complex (1). Hydrogen bonds are drawn as dashed lines. Hydrogen atoms not related to hydrogen bonds are omitted for clarity. 


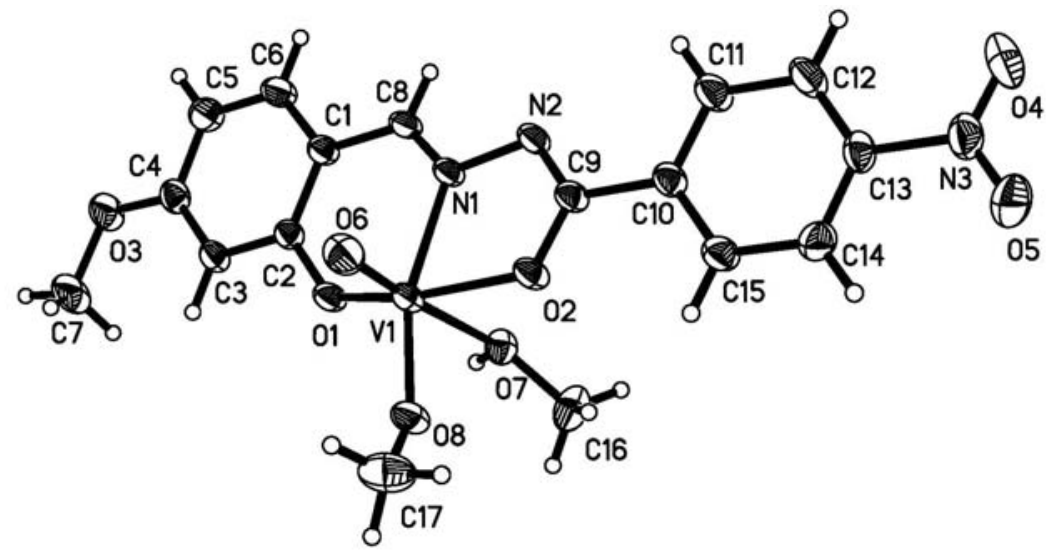

Figure 5. Molecular structure of complex (2) at 30\% probability displacement.

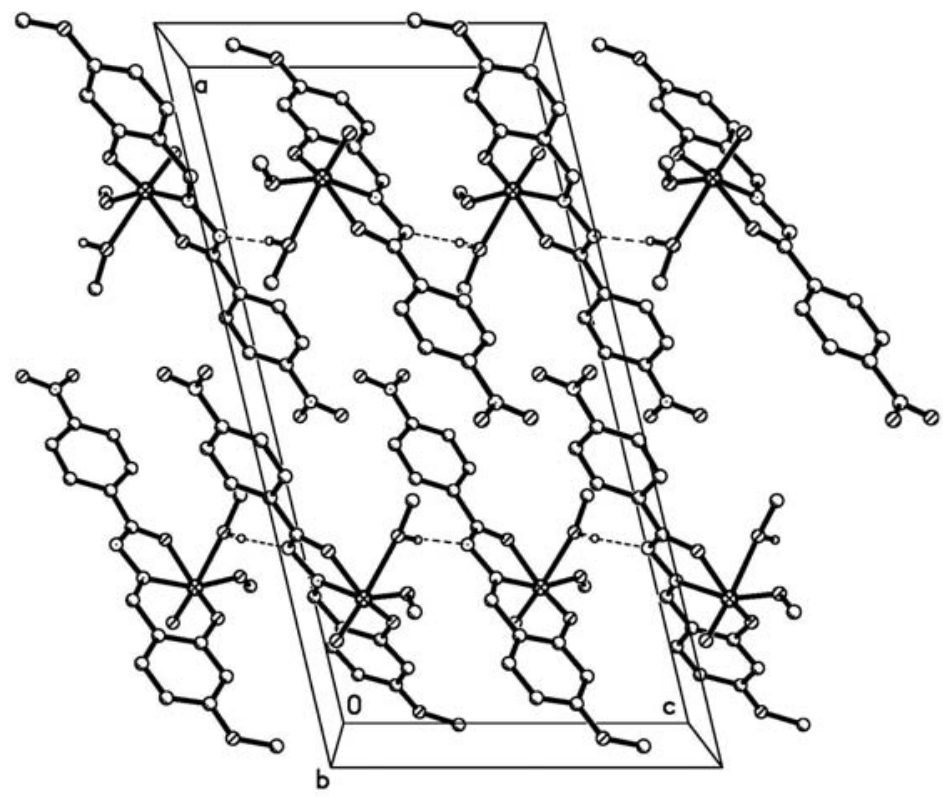

Figure 6.Molecular packing of complex (2). Hydrogen bonds are drawn as dashed lines. Hydrogen atoms not related to hydrogen bonds are omitted for clarity.

\section{CONCLUSION}

In summary, two new methanol and methanolate-coordinated mononuclear oxovanadium(V) complexes derived from similar aroylhydrazone ligands have been prepared and structurally characterized by single crystal X-ray diffraction method, as well as elemental analysis and FTIR spectroscopic technique. The aroylhydrazone ligands coordinate to the VO core through the enolate oxygen, phenolate oxygen and azomethine nitrogen. Thermal stability of the complexes have also been studied. 
Supplementary data. The crystallographic data for the structures have been deposited with the Cambridge Crystallographic Data Centre (CCDC 974790 for (1) and 974791 for (2)). Copies of the data can be obtained free of charge on application to the Director, CCDC, 12 Union Road, Cambridge CB2 1EZ, UK (e-mail for deposition: deposit@ccdc.cam.ac.uk).

\section{REFERENCES}

1. Guilherme, L.R.; Massabni, A.C.; Cuin, A.; Oliveira, L.A.A.; Castellano, E.E.; Heinrich, T.A.; Costa-Neto, C.M. J. Coord. Chem. 2009, 62, 1561.

2. Ashiq, U.; Ara, R.; Mahroof-Tahir, M.; Maqsood, Z.T.; Khan, K.M.; Khan, S.N.; Siddiqui, H. Chem. Biodivers. 2008, 5, 82.

3. Monga, V.; Thompson, K.H.; Yuen, V.G.; Sharma, V.; Patrick, B.O.; McNeill, J.H.; Orvig, C. Inorg. Chem. 2005, 44, 2678.

4. Ogwuegbu, M.O.C. Bull. Chem. Soc. Ethiop. 1999, 13, 113.

5. Abebaw, A.; Chandravanshi, B.S. Bull. Chem. Soc. Ethiop. 1996, 10, 121.

6. Rostami, A.; Atashkar, B. Catal. Commun. 2015, 58, 80.

7. Pradhan, M.; Roy, A.; Sinha, A.K.; Sahoo, R.; Deb, D.; Pal, T. Dalton Trans. 2015, 44, 1889.

8. Ebrahimipour, S.Y.; Abaszadeh, M.; Castro, J.; Seifi, M. Polyhedron 2014, 79, 138.

9. Saha, U.; Si, T.K.; Nandi, P.K.; Mukherjea, K.K. Inorg. Chem. Commun. 2013, 38, 43.

10. Cheng, X.-S.; Zhang, J.-C.; You, Z.-L.; Wang, X.; Li, H.-H. Transition Met. Chem. 2014, 39, 291.

11. Zhang, J.-C.; Li, Y.-N.; Huang, D.; Xu, F.-Y.; Cheng, X.-S.; You, Z.-L. Chinese J. Inorg. Chem. 2014, 30, 425.

12. You, Z.-L.; Xian, D.-M.; Zhang, M. CrystEngComm 2012, 14, 7133.

13. Sheikhshoaie, I.; Shamspur, T.; Mostafavi, A.; Ebrahimipur, S.Y. Bull. Chem. Soc. Ethiop. 2012, 26, 65.

14. Yaul, A.R.; Dhande, V.V.; Pethe, G.B.; Aswar, A.S. Bull. Chem. Soc. Ethiop. 2014, 28, 255.

15. Naeimi, H.; Heidarnezhad, A. Bull. Chem. Soc. Ethiop. 2015, 29, 117.

16. Huo, Y.; Ye, Y.-T.; Cheng, X.-S.; You, Z.-L. Inorg. Chem. Commun. 2014, 45, 131.

17. Ren, J.-Q.; Jiao, Q.-Z.; Wang, Y.-N.; Xu, F.-Y.; Cheng, X.-S.; You, Z.-L. Chinese J. Inorg. Chem. 2014, 30, 640.

18. Amini, M.; Arab, A.; Soleyman, R.; Ellern, A.; Woo, L.K. J. Coord. Chem. 2013, 66, 3770.

19. Romanowski, G.; Wera, M. Polyhedron 2013, 50, 179.

20. Cordelle, C.; Agustin, D.; Daran, J.C.; Poli, R. Inorg. Chim. Acta 2010, 364, 144.

21. Nair, R.S.; Kuriakose, M.; Somasundaram, V.; Shenoi, V.; Kurup, M.R.P.; Srinivas, P. Life Sci. 2014, 116, 90.

22. Li, A.-M. J. Coord. Chem. 2014, 67, 2076.

23. Bruker, SMART and SAINT, Bruker AXS Inc.: Madison, Wisconsin, USA; 2002.

24. Sheldrick, G.M. SADABS Program for Empirical Absorption Correction of Area Detector, University of Göttingen: Germany; 1996.

25. Sheldrick, G.M. Acta Crystallogr. 2008, A64, 112.

26. Geary, W.J. Coord. Chem. Rev. 1971, 7, 81.

27. Sarkar, A.; Pal, S. Inorg. Chim. Acta 2008, 361, 2296.

28. Sarkar, A.; Pal, S. Polyhedron 2007, 26, 1205.

29. Zhao, Y.; Han, X.; Zhou, X.-X.; Li, H.-H.; You, Z.-L. Chinese J. Inorg. Chem. 2013, 29, 867.

30. You, Z.-L.; Shi, D.-H.; Zhang, J.-C.; Ma, Y.-P.; Wang, C.; Li, K. Inorg. Chim. Acta 2012, 384, 54 . 